\title{
Weight loss technology for people with treated type 2 diabetes: a randomized controlled trial
}

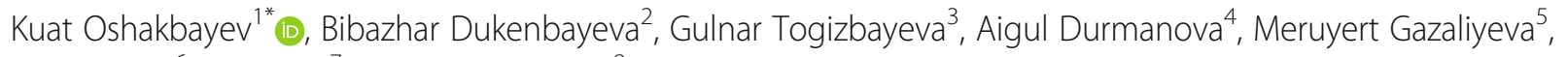
Abdul Sabir ${ }^{6}$, Aliya Issa ${ }^{7}$ and Alisher Idrisov ${ }^{8}$

\begin{abstract}
Background: The prevalence of type 2 diabetes is increasing in worldwide despite the development of new treatment methods. Aim of the study was to evaluate a weight loss method on body composition, glycemic, lipid and hormone profiles, blood pressure and reactive oxygen species in people with treated type 2 diabetes.

Methods: A 24-week open, prospective, randomized, controlled clinical trial including 272 adult patients with treated type 2 diabetes was performed. The patients were divided in two groups: Main group consisted of 208 patients who followed a method including a calorie restriction diet and optimal physical activity; Control included 64 patients who received conventional drug treatment with weight loss. Main Outcome Measures were weight loss, fasting glucose and 2-hour oral glucose tolerance test (OGTT), HbA1c. Secondary endpoints were blood pressure, lipid and insulin blood levels.

Results: At 24 weeks, patients in Main weight lost between 8-18 kg (10-21\%); their body mass index significantly decreased $(-4.2 \mathrm{~kg} / \mathrm{m} 2)$ as well as their waist circumference $(-13 \mathrm{~cm})$ compared to Control. In Main weight loss was achieved fatty mass reduction. In Main fasting glucose and OGTT, HbA1c, blood pressure, reactive oxygen species decreased significantly, whereas hemoglobin levels and heel bone mineral density increased. In Main blood insulin levels decreased by $72.0 \%$, cortisol levels decreased by $40.7 \%$, while testosterone levels in men increased by 2.4 times from baseline. The application of the weight loss method led to a decrease in drug doses leading to their complete withdrawal.
\end{abstract}

Conclusions: The results of this study show the beneficial role of a weight loss method in improving glycemic, lipid and hormone profiles, electrolyte and biochemical indices, blood pressure, reactive oxygen species and bone mineral density in patients with treated type 2 diabetes.

Trial registration: ClinicalTrials.gov Identifier: NCT02503865. Retrospectively registered November 2015.

Keywords: Type 2 diabetes, Weight loss, Restriction diet, Glycemic/lipid and hormone profiles, Lipid/protein oxidation

\footnotetext{
* Correspondence: okp.kuat@gmail.com

${ }^{1}$ Metabolic Syndrome Department, Nazarbayev University Medical Center,

Street Baitursynuly, 5, fl. 601, 010000 Astana, Kazakhstan

Full list of author information is available at the end of the article
} 


\section{Background}

In 2015, an estimated 422 million people had diabetes worldwide [1], with T2D making up to about $90 \%$ of the cases [2]. Diabetes is a major cause of blindness, kidney failure, heart attacks, stroke and lower limb amputation, and affects $8.5 \%$ of the adult population with equal prevalence in both women and men [3]. Diabetes triples the risk of cardiovascular diseases and doubles the risk of death [4]. Prevalence of T2D is increasing worldwide despite the development of new drugs.

Obesity/overweight is a major risk factor for T2D $[5,6]$. For instance, just $5 \%$ weight reduction improves glycemic control in people with T2D $[1,6]$. Effectiveness and types of weight loss approches in people with T2D are increasingly reported in the literature. and many tested weight loss methods have been proved to be less effective [4-6]. A systematic review of weight loss interventions in people with T2D revealed that interventions including very lowcalorie diets along with moderate physical activity produced the largest effect [7, 8]. Although numerous studies have attempted to identify the optimal mix of lifestyle behavior for people with T2D, the optimal level of caloric restriction in T2D is not well defined. Moreover many of them do not include taking of sodium and androgen-safety behavior during weight loss. We have obtained positive results in people with T2D including those who are insulin-dependent, using a weight loss method that we developed. Objective: to evaluate the effects of our weight loss method on glycemic, lipid and hormone profiles, blood pressure (BP), reactive oxygen species level (ROS) and body composition in people with treated T2D in a 24-week open, prospective, randomized, controlled clinical trial.

\section{Methods}

\section{Participants}

The study enrolled 296 adult people aged from 25 to 74 years with treated T2D. All the participants had hypertension. The patients were randomly recruited and divided in two groups: Main group (Experimental): nonpharmacological weight loss; Control group (Conventional): conventional drug therapy with weight loss medication.

Main group included 224 patients who were taking antidiabetes drugs at least 3 years prior to first visit. Of these 224 patients, $7.1 \%$ dropped out prior to the study completion: 6 patients moved to live on another town, 8 patients refused treatment through the weight loss method and 2 patients were excluded due to noncompliance. Therefore 208 patients (109 women, mean age $47.7 \pm 1.8$ years) with T2D were followed up. All these 208 patients had abdominal obesity with waist circumference (WC) $99.2 \pm 0.6 \mathrm{~cm}$ and body mass index (BMI) $29.6 \pm 0.4 \mathrm{~kg} / \mathrm{m}^{2} .152$ patients were on insulin (24-72 units/day), 56 patients were treated with Metformin, Sulfonylurea, incretines [exenatide (Byetta, Bydureon), liraglutide (Victoza)], Pioglitazone in different combinations.

Control group included 72 patients; $11.1 \%$ of them dropped out prior to study completion (2 patients moved to another town, 5 patients refused treatment, and one was excluded due to noncompliance). Thus 64 patients ( 34 women, mean age $46.5 \pm 2.1$ years, WC 98.9 $\pm 0.8 \mathrm{~cm}$, BMI $29.3 \pm 0.9 \mathrm{~kg} / \mathrm{m}^{2}$ ) were recruited and treated with conventional drug therapy including hypoglycemics (metformin 500-1500 mg/day, exenatide 5$10 \mu \mathrm{g} /$ day), lipid lowering (atorvastatin $40 \mathrm{mg} /$ day), antihypertensive (lisinopril $20 \mathrm{mg} /$ day, calcium channel blockers referring to benzodiazepines $90 \mathrm{mg} /$ day) and anti-inflammatory (acetylsalicylate acid up to $2 \mathrm{~g} /$ day and/or thienopyridine class antiplatelet agent $75 \mathrm{mg}$ per day) drugs, and a gastrointestinal lipase inhibitor for obesity management (orlistat $360 \mathrm{mg}$ /day orally within one hour of completing a meal). 41 of these 64 patients were on insuli (24-72 U/day).

The study was carried out in Kazakhstan between January 2003 and December 2014 at the Scientific Research Institute of Cardiology and Internal Diseases (Almaty) and at the Nazarbayev University Medical Center (Astana).

\section{Inclusion criteria}

1) written informed consent form; 2) diagnosis of $T 2 D \geq$ 3 -year and treatment with glucose lowering therapy; 3) triglycerides $>1.7 \mathrm{mmol} / \mathrm{l}$ or cholesterol $>5.6 \mathrm{mmol} / \mathrm{l}$ or both); 4) body fat $>21$; 5) WC $>94.0 \mathrm{~cm}$ in men or $>$ $80.0 \mathrm{~cm}$ in women; 6) ongoing treatment with antihypertensive treatment; 7) weight loss treatment for 24 weeks and follow-up $\geq 24$ weeks.

\section{Outcome measures}

Primary endpoints: weight loss over 24 weeks, fasting blood glucose and 2-hour oral glucose tolerance test (OGTT), HbA1c. Secondary endpoints were systolic/diastolic BP, blood lipids, blood insulin levels.

\section{Randomization}

An independent statistician unconnected with clinical practice prepared randomization lists of patients with T2D using computer generated random numbers (SPSS for Windows v.21.0: An IBM Company, Armunk, NY).

\section{Analytical assessment}

T2D was diagnosed according to the criteria reported in the WHO/IDF 2006 consultation [WHO/IDF consultation. Geneva, Switzerland, 2006]. Hypertension was diagnosed by BP readings and from medical records. Abdominal obesity was assessed by WC using the standards for Asians developed by the International Diabetes 
Federation (2005). Physical activity of patients was assessed by the number of steps measured by pedometers (Hoffmann-La Roche Ltd, Basel, Switzerland).

Anthropometrical indicators included age (years), weight ( $\mathrm{kg})$, BMI $\left(\mathrm{kg} / \mathrm{m}^{2}\right)$, WC $(\mathrm{cm})$. Body composition parameters including fat mass (in \% of total body weight and total $\mathrm{kg}$ ), visceral fat rating (units), fat free mass $(\mathrm{kg})$, total body water (\% and $\mathrm{kg}$ ), muscle mass (\% and $\mathrm{kg}$ ), bone mass (\% and $\mathrm{kg}$ ), metabolic age (years), basal metabolic rate ( $\mathrm{kcal} /$ day), and bioimpedance (Ohms) were measured using a TanitaSC330S Body Composition Analyzer (Tanita Corp., Tokyo, Japan). On the same blood samples, complete blood cell count, erythrocyte sedimentation rate, urea, creatinine, glucose, electrolytes, total cholesterol, triglycerides, total proteins with fractions, fibrinogen, bilirubin, hepatic enzyme levels and HbA1c [normal: $<39 \mathrm{mmol} / \mathrm{mol}$ (5.7\%); prediabetes: 39 to $48 \mathrm{mmol} / \mathrm{mol}$ (5.7-6.5\%), diabetes: $\geq 48 \mathrm{mmol} /$ mol (6.5\%)] were determined. Post oral glucose load insulin sensitivity was determined using the 2-hour OGTT with $75 \mathrm{~g}$ of glucose. Ultrasound images (GE Vivid 7 Ultrasound; GE Healthcare Worldwide USA, Michigan) were obtained, and heel bone mineral density (HBMD) was measured using a Lunar Achilles Express Ultrasound densitometry (GE Healthcare USA, Madison; at normal range 100.0 \pm 15.0 Units). Sodium excretion was considered high when $>150.0 \mathrm{mmol} / \mathrm{L}$ for both genders in 24-hour collected urine (normal 135-145 mmol/L).

For ROS we measured malondialdehyde (MDA, a marker of lipid peroxidation and degradation product of oxidized fatty acids), superoxide dismutase and catalase (antioxidant enzymes), and advanced oxidation protein products (AOPP, markers of protein oxidation). MDA $(\mu \mathrm{mol} / \mathrm{L})$ was measured using a thiobarbituric acidreactive substance assay as described by Yagi and modified by Ohkawa [9].

Antioxidant enzymes were determined in erythrocyte hemolysates, in which hemoglobin concentration was assayed using Drabkin's method. Superoxide dismutase was measured by the method of Misra and Fridrovich [10]. Catalase was measured at $\lambda=240 \mathrm{~nm}$ at $25^{\circ} \mathrm{C}$; catalase activity was expressed in U/g and one unit is considered as the amount of the enzyme which decomposes $1 \mathrm{~g}$ of $\mathrm{H}_{2} \mathrm{O}_{2}$ in $1 \mathrm{~min}$ at $25{ }^{\circ} \mathrm{C}$ in $\mathrm{pH}=7.0$. AOPP $(\mu \mathrm{mol} / \mathrm{L})$ were measured by adding $40 \mu \mathrm{L}$ of plasma to a $190 \mu \mathrm{L}$ of mixture of $81 \%$ phosphate buffer solution, $10 \%$ glacial acetic acid and $4 \% 1.16 \mathrm{mmol}$ solution of KI, followed by 2 min absorbance at $340 \mathrm{~nm}$ on a plate reader Multiscan Ascent using a spectrophotometric method. Chloramine$\mathrm{T}$ solution was used as calibrator [11].

\section{Hormonal assays}

Fasting serum insulin (nU/L) was determined by immunoassay (Immunotech Insulin Irma kit, Prague, Czech Republic). Hyperinsulinemia was considered $>12.5 \mathrm{nU} / \mathrm{L}$.
The Homeostasis Model Assessment insulin resistance indexes (HOMA-IR) was used as surrogate measure of insulin sensitivity as follows: HOMA-IR $=(($ fasting insulin in $\mathrm{nU} / \mathrm{L}) \times($ fasting glucose in $\mathrm{mmol} / \mathrm{l}) / 22.5)$. Insulin resistance was considered if the index was $>2$.

Fasting serum cortisol was determined using solidphase chemiluminescent enzyme immunoassay (Cortisol-IFA-Best kit, Russia) on Sunrise Tecan-5082 (Austria, Gmbh) at $450 \mathrm{~nm}$ (limit of detection was $5 \mathrm{nmol} / \mathrm{L}$; measurement ranges were $0-1200 \mathrm{nmol} / \mathrm{L}$. normal ranges $150-660 \mathrm{nmol} / \mathrm{L}$ ).

Fasting total serum testosterone was assayed using standard solid-phase radioimmunoassay (Biermann DPC, Germany) procedures with a limit of detection $<4 \mathrm{ng} / \mathrm{dL}$, 290-1290 ng/dL were normal values.

The hormones were investigated three days after stopping the treatment.

\section{Intervention}

For weight loss in Main group we used the "Analimentary detoxication" (ANADET) weight loss method [12], including calorie restriction to $100-150 \mathrm{kcal} /$ day with fat-free vegetables (tomatoes and cucumbers), salt intake limitation to 5-6 g/day, walking at least 8000 steps/day, and sexual self-restraint. The exercise was promoted to favor blood circulation and decrease metabolic intoxication. The weight loss method consisted of two courses of "treatment" that lasted 14-28 days each according to the principle "the slower the weight loss, the longer its duration", with a two-week interruption between the courses. Then the patients followed a diet where they ate one meal a day without any food restriction. A combination of in-person conversations and telephone calls were conducted during the 24-week study period and a 24-week follow-up period. Weight loss results were assessed by Tanita-SC330S, BMI, WC, and skinfold thickness measurement method $(\mathrm{cm})$ in abdominal and the back areas. The method maintains an achieved target weight loss for $\geq 24$ weeks.

\section{Statistics}

The two-side Student's $t$-test and Odds ratios (ORs) with 95\% Confidence intervals (CIs) were used. The study data were tested against the normal distribution and are presented in Tables as Mean \pm Standard Error of the Mean $(\mathrm{M} \pm \mathrm{SEM})$, and in Figures as Mean \pm Standard Deviation $(\mathrm{M} \pm \mathrm{SD})$. The formula for the SEM is the SD divided by the square root of the sample size. The correlation analysis ( $r$ ) and an analysis of covariance (ANCOVA) model were used. $P$-value of $<0.05$ was set as significant and $<0.0001$ was set as highly significant. Statistical analysis was performed using SPSS ver.21.0 for Windows (SPSS: An IBM Company, Armunk, NY) and Microsoft Excel-2013. 


\section{Results}

Baseline/24-week treatment results concerning anthropometrical data, body composition, and metabolic data in the compared groups are shown in Table 1. In Main group weight loss varied from 8 to $18 \mathrm{~kg}$ (-10-21\% from baseline) and was higher than Control at 24-week $(-12.8 \pm$ $0.8 \mathrm{~kg}$ vs. $-3.2 \pm 0.9 \mathrm{~kg}$, respectively; $P<0.00001)$. In Main we observed a significantly decrease in BMI $\left(-4.2 \mathrm{~kg} / \mathrm{m}^{2}\right)$ and WC $(-13 \mathrm{~cm})$, skinfold thickness in abdomen and the back areas $(-1.4 \mathrm{~cm})$. Figure 1 shows adjusted mean differences in Main vs. Control from baseline in Anthropometrical data at 24-week. In Main weight loss was due to reduction of fat mass only (before, $25.41 \pm 0.65 \mathrm{~kg}$, and after, $12.38 \pm 0.68 \mathrm{~kg}, P<0.00001)$. Percentages of total body water and muscle masses tended to increase significantly, and the percentage of bone mass increased significantly too. Lean body mass (fat-free mass) did not change significantly during weight loss $(P=0.9225)$. Figure 2 shows adjusted mean difference from baseline Body composition in group Main vs Control at 24-week.

In Main group there was an inverse relationship between Fat mass percentage and Metabolic age/Basal metabolic rate $(r=-0.58, P=0.0014$ and $r=-0.68, P=0.0009$, respectively). Bioimpedance, electrical conductivity also improved.
The ANADET (Main group) led to a 15-19\% decrease in systolic/diastolic BP in 199 patients (95.8\%) (Table 2). Fasting Glucose, 2-hour OGTT, HbA1c and systolic BP decreased in Control, but to a lesser extent. In Control diastolic BP decreased less and did not reach the level recommended by the American Heart Association (2014).

Hemoglobin, Catalase and HBMD levels did not change in Control, whereas in Main group hemoglobin levels increased by $+9.5 \%$ and erythrocyte sedimentation rate and eosinophilia decreased from baseline by 67.5 and $66.0 \%$, respectively. In Main group there was a reduction of fasting glucose $(-47.9 \%)$, OGTT (2.2-fold), HbA1c (-22\%), Cholesterol $(-22.0 \%)$, Triglycerides $(-66.5 \%)$, total Fibrinogen $(-51.1 \%)(P<0.0001)$. In Control HbA1c decreased by $8 \%(P<0.05)$, but did not reach to the normal.

The oxidative products of lipids and proteins were also normalized in Main group, where MDA decreased by $30.9 \%$, AOPP by $31.9 \%$, and Superoxide dismutase increased by $44.4 \%$ and Catalase by $19.3 \%$ from baseline. Urine sodium excretion decreased by $80.3 \%$ after weight loss, while blood sodium increased by 6.7\%. HBMD increased significantly $(+19.7 \%)$ from baseline $(P<0.00001)$. In contrast, in Control there were a

Table 1 Anthropometrical data, body composition, Metabolic age, Basal metabolic rate in people with treated T2D before (baseline) and after treatment (24-week) within Main (Experimental) and Control (Conventional) groups (M \pm SEM)

\begin{tabular}{|c|c|c|c|c|c|}
\hline \multirow[t]{2}{*}{ Variables } & & \multicolumn{2}{|c|}{ Main group, $n=208$} & \multicolumn{2}{|c|}{ Control group, $n=64$} \\
\hline & & Baseline & 24-Week & Baseline & 24-Week \\
\hline Passport age (years) & & $47.69 \pm 1.82$ & & $46.54 \pm 2.08$ & \\
\hline Weight (kg) & & $84.52 \pm 0.75$ & $72.44 \pm 1.02^{* *}$ & $84.49 \pm 0.81$ & $81.35 \pm 1.23^{*}$ \\
\hline BMI $\left(\mathrm{kg} / \mathrm{m}^{2}\right)$ & & $29.60 \pm 0.39$ & $25.40 \pm 0.37^{* *}$ & $29.30 \pm 0.47$ & $28.04 \pm 0.55$ \\
\hline$W C(\mathrm{~cm})$ & & $99.18 \pm 0.56$ & $86.13 \pm 0.93^{* *}$ & $98.91 \pm 0.83$ & $95.38 \pm 0.78^{*}$ \\
\hline \multirow{2}{*}{$\begin{array}{l}\text { Skinfold thickness in } \\
\text { the areas of }(\mathrm{cm}) \text { : }\end{array}$} & Abdomen & $3.96 \pm 0.04$ & $2.52 \pm 0.05^{* *}$ & $4.02 \pm 0.07$ & $3.69 \pm 0.08^{*}$ \\
\hline & The back & $4.41 \pm 0.04$ & $3.14 \pm 0.05^{* *}$ & $4.38 \pm 0.06$ & $4.06 \pm 0.07^{*}$ \\
\hline Fat mass (\%) & & $30.06 \pm 0.52$ & $18.47 \pm 0.67^{* *}$ & $29.73 \pm 0.88$ & $28.04 \pm 0.92$ \\
\hline Fat mass (kg) & & $25.41 \pm 0.65$ & $13.38 \pm 0.68^{* *}$ & $25.12 \pm 0.97$ & $22.87 \pm 1.12$ \\
\hline Fat free mass $(\mathrm{kg})$ & & $59.11 \pm 0.32$ & $59.06 \pm 0.41$ & $59.37 \pm 0.79$ & $58.68 \pm 0.80$ \\
\hline Total body water (kg) & & $44.58 \pm 0.26$ & $45.13 \pm 0.32$ & $44.65 \pm 0.44$ & $44.81 \pm 0.46$ \\
\hline Total body water (\%) & & $52.74 \pm 0.35$ & $62.29 \pm 0.43^{* *}$ & $52.84 \pm 0.57$ & $54.94 \pm 0.62^{*}$ \\
\hline Muscle mass (kg) & & $54.22 \pm 1.14$ & $55.39 \pm 1.96$ & $54.21 \pm 1.76$ & $54.19 \pm 1.98$ \\
\hline Muscle mass (\%) & & $64.15 \pm 1.21$ & $76.46 \pm 1.62^{* *}$ & $64.27 \pm 1.71$ & $66.48 \pm 1.82$ \\
\hline Bone mass (kg) & & $3.18 \pm 0.06$ & $3.09 \pm 0.10$ & $3.17 \pm 0.09$ & $3.07 \pm 0.10$ \\
\hline Bone mass (\%) & & $3.76 \pm 0.08$ & $4.26 \pm 0.09^{* *}$ & $3.75 \pm 0.09$ & $3.78 \pm 0.11$ \\
\hline Metabolic age (years) & & $52.12 \pm 1.52$ & $42.31 \pm 1.68^{* *}$ & $52.01 \pm 1.87$ & $50.11 \pm 1.92$ \\
\hline Basal metabolic rate (kcal/day) & & $1702.4 \pm 43.25$ & $1401.6 \pm 48.56^{* *}$ & $1700.6 \pm 50.45$ & $1639.2 \pm 55.44$ \\
\hline Bioimpedance (ohms) & & $512.5 \pm 9.25$ & $465.5 \pm 9.15^{*}$ & $507.4 \pm 14.43$ & $496.2 \pm 13.28$ \\
\hline
\end{tabular}

Abbreviations: $B M I$ body mass index, $M$ mean, SEM standard error of the mean, WC waist circumference, T2D type 2 diabetes ${ }^{*} P$-value of $<0.05$, and

${ }^{* *} P<0.0001$ were set as significant between baseline and 24-week treatment within group comparison 


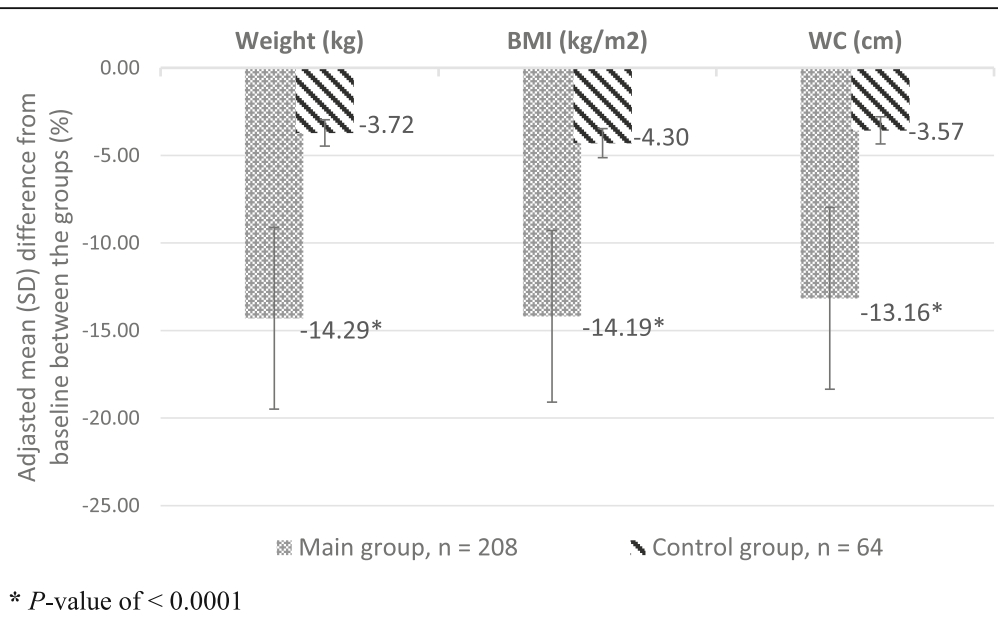

Fig. 1 Adjusted mean differences in Anthropometrical data between baseline and week 24 in people with treated T2D in Main versus Control groups (SPSS, ANCOVA), $P<0.0001(\mathrm{M} \pm \mathrm{SD})$

significant increase in eosinophilia, MDA, AOPP, and urine sodium and $\mathrm{s}$ decrease in blood sodium.

In Main after treatment blood insulin decreased by $72.0 \%$, cortisol decreased by $40.7 \%$, whereas blood testosterone in men $(n=99)$ increased 2.4-fold from baseline (Table 3). In Control, the positive changes in hormones were not so evident. For instance, insulin in Main decreased 3.6-fold from baseline after treatment, whereas in Control it decreased only 1.4-fold (95\%; OR 2.6, CI 2.1-3.1). Although in Control insulin levels did not decrease to the normal. In addition, cortisol and testosterone levels did not change significantly in Control.

The Table 3 proves that in Main group tissue insulin sensitivity improved following treatment, and IR (HOMA-IR index) decreased significantly 6.8 -fold from baseline, whereas in Control it only decreased only 2fold (95\%; OR3.2, CI2.8-3.3). In Control the HOMA-IR index did not reach normal values (Fig. 3).
During the first 2-5 days of treatment most of the patients in Main complained of hunger, slight dizziness, weakness, lower extremity and abdominal muscle tremor, warm feeling in the umbilical/solar plexus areas, and psychogenic fear due to changed eating behavior, which all disappeared in the following days. 3-5 days after the start of the ANADET patients' urine became turbid, muddy and intensively colored (dark). These urine appearance persisted for several days. Urine microscopy showed organic salts such as oxalates, urates, phosphates, and carbonates of calcium and magnesium. An increase in body temperature and blood leukocyte count was observed between 4 and 14 days after the start of ANADET. The comorbidity symptoms were also regressed gradually. The patients noticed a physical relief, increase in physical/ mental workability, and exercise tolerance.

As the clinical status of the patients was improving, the previous anti-diabetic, antihypertensive and

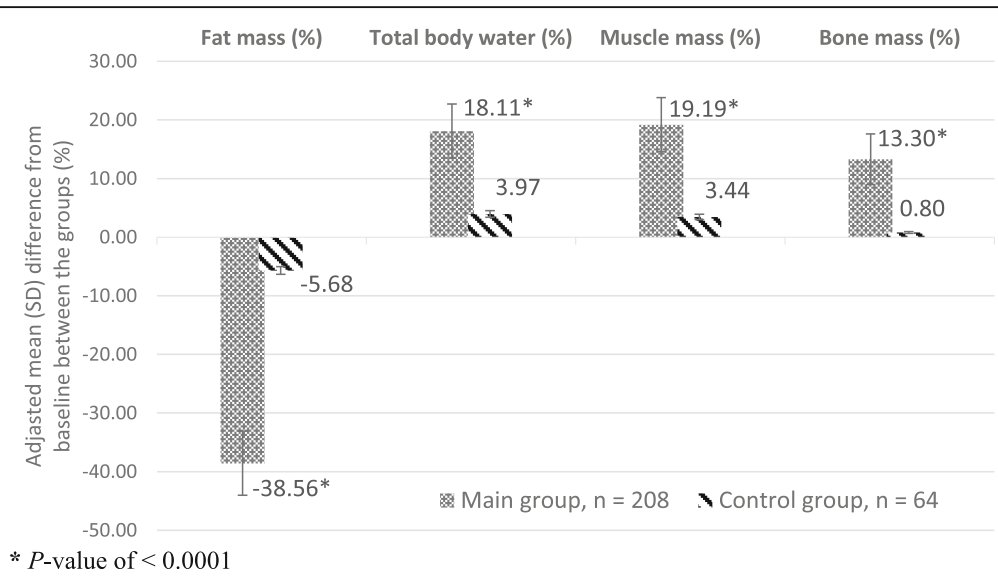

Fig. 2 Adjusted mean differences in Body composition between baseline and week 24 in people with treated T2D in Main versus Control groups (SPSS, ANCOVA), $P<0.0001(\mathrm{M} \pm \mathrm{SD})$ 
Table 2 Blood pressures, Blood biochemical parameters, Lipid and protein oxidative products, Sodium excretion rate, and HBMD in people with treated T2D before (baseline) and after treatment (24-week) within the Main (Experimental) and Control (Conventional) groups $(\mathrm{M} \pm \mathrm{SEM})$

\begin{tabular}{|c|c|c|c|c|}
\hline \multirow[t]{2}{*}{ Variables } & \multicolumn{2}{|l|}{ Main group, $n=208$} & \multicolumn{2}{|l|}{ Control group, $n=64$} \\
\hline & Baseline & 24-week & Baseline & 24-week \\
\hline Systolic blood pressure $(\mathrm{mmHg})$ & $154.3 \pm 1.22$ & $120.4 \pm 0.67^{* *}$ & $150.4 \pm 1.76$ & $128.7 \pm 2.17^{* *}$ \\
\hline Diastolic blood pressure $(\mathrm{mmHg})$ & $98.7 \pm 0.75$ & $80.92 \pm 0.63^{* *}$ & $98.1 \pm 0.98$ & $93.2 \pm 1.29^{*}$ \\
\hline Hemoglobin (g/L) & $126.5 \pm 0.68$ & $138.9 \pm 0.62^{* *}$ & $127.1 \pm 0.71$ & $127.4 \pm 0.72$ \\
\hline ESR (mm/Hour) & $23.4 \pm 0.64$ & $7.66 \pm 0.26^{* *}$ & $22.9 \pm 0.70$ & $24.8 \pm 0.75^{*}$ \\
\hline Eosinophilia (\%) & $5.35 \pm 0.21$ & $1.82 \pm 0.14^{* *}$ & $5.29 \pm 0.29$ & $6.08 \pm 0.30^{*}$ \\
\hline Glucose (mmol/L) & $8.64 \pm 0.19$ & $4.50 \pm 0.11^{* *}$ & $8.58 \pm 0.24$ & $6.04 \pm 0.21^{* *}$ \\
\hline 2-hour OGTT (mmol/L) & $14.5 \pm 0.28$ & $6.7 \pm 0.19^{* *}$ & $14.1 \pm 0.33$ & $8.21 \pm 0.42^{* *}$ \\
\hline $\mathrm{HbA1c}(\mathrm{mmol} / \mathrm{mol}$ and \%) & $52.0 \pm 0.68(6.91 \pm 0.09)$ & $35.0 \pm 0.52^{* *}(5.39 \pm 0.08)$ & $52.0 \pm 1.13(6.89 \pm 0.15)$ & $46.0 \pm 1.15^{*}(6.38 \pm 0.16$ \\
\hline Cholesterol (mmol/L) & $5.82 \pm 0.07$ & $4.54 \pm 0.05^{* *}$ & $5.77 \pm 0.09$ & $5.47 \pm 0.11^{*}$ \\
\hline Triglyceride (g/L) & $2.42 \pm 0.08$ & $0.81 \pm 0.05^{* *}$ & $2.21 \pm 0.08$ & $1.92 \pm 0.12^{*}$ \\
\hline Total Fibrinogen (g/L) & $4.52 \pm 0.07$ & $2.21 \pm 0.06^{* *}$ & $4.58 \pm 0.09$ & $4.05 \pm 0.18^{*}$ \\
\hline $\mathrm{MDA}(\mu \mathrm{mol} / \mathrm{L})$ & $48.47 \pm 0.68$ & $33.48 \pm 0.29^{* *}$ & $46.99 \pm 0.75$ & $50.46 \pm 0.79^{*}$ \\
\hline SOD (U/mg) & $53.83 \pm 0.54$ & $77.71 \pm 0.67^{* *}$ & $52.91 \pm 0.65$ & $56.87 \pm 0.97^{*}$ \\
\hline Catalase (U/g) & $22.17 \pm 0.42$ & $26.44 \pm 0.46^{* *}$ & $23.81 \pm 0.49$ & $25.17 \pm 0.68$ \\
\hline AOPP $(\mu \mathrm{mol} / \mathrm{L})$ & $266.8 \pm 12.6$ & $181.8 \pm 7.8^{* *}$ & $262.4 \pm 13.6$ & $295.6 \pm 13.9^{*}$ \\
\hline Sodium in the urine $(\mathrm{mmol} / \mathrm{L})$ & $164.1 \pm 2.8$ & $32.4 \pm 1.9^{* *}$ & $164.1 \pm 2.8$ & $182.4 \pm 3.5^{* *}$ \\
\hline Sodium in the blood (mmol/L) & $134.4 \pm 0.32$ & $143.7 \pm 0.38^{* *}$ & $135.1 \pm 0.35$ & $134.1 \pm 0.34^{*}$ \\
\hline HBMD (Units) & $77.83 \pm 1.86$ & $93.2 \pm 1.37^{* *}$ & $78.78 \pm 1.92$ & $76.87 \pm 1.88$ \\
\hline
\end{tabular}

Abbreviations: $A N A D E T$ analimentary detoxication, $A O P P$ advanced oxidation protein products, ESR erythrocyte sedimentation rate, $H B M D$ heel bone mineral density, $M$ mean, MDA malondialdehyde, OGTT oral glucose tolerance test, SOD superoxide dismutase, SEM standard error of the mean, T2D type 2 diabetes ${ }^{*} P$-value of $<0.05$, and

${ }^{* *} P<0.0001$ were set as significant between baseline and 24-week treatment within group comparison

other symptomatic conventional medications were adequately decreased from 2 to 3 days after starting ANADET. By days 7 to 10 after the treatment start, the drugs were stopped completely. There was no recurrence of T2D at 6 months follow-up period if the patients had not regained overweight. If a patient regained overweight, symptoms of T2D gradually manifested again, and once again disappeared once the overweight was lost again.

\section{Discussion}

Our data show that weight loss method (10 to $21 \%$ fat loss) including calorie restriction (100-150 kcal/day), fat-free vegetables and salt intake (5-6 g/day), optimal physical activity, and sexual self-restraint over a 24-week period is a safe, well tolerated, and acceptable nutritional therapy option for subjects with T2D. Our study confirms that weight loss can lead to normalization of $\mathrm{BP}$ [13]. ANADET repealed insulin resistance, improved

Table 3 Immunoassays of blood Insulin, HOMA-IR, Cortisol and Testosterone (in men) in people with treated T2D before (baseline) and after treatment (24-week) within Main (Experimental) and Control (Conventional) groups (M \pm SEM)

\begin{tabular}{|c|c|c|c|c|}
\hline \multirow[t]{2}{*}{ Variables } & \multicolumn{2}{|c|}{ Main group, $n=208$} & \multicolumn{2}{|c|}{ Control group, $n=64$} \\
\hline & Baseline & 24-week & Baseline & 24-week \\
\hline Immunoassay insulin (nU/L) & $23.2 \pm 1.0$ & $6.5 \pm 0.3^{*}$ & $20.9 \pm 1.2$ & $15.0 \pm 1.2^{*}$ \\
\hline Immunoassay cortisol (nmol/L) & $751.2 \pm 6.7$ & $445.7 \pm 5.3^{*}$ & $747.2 \pm 8.9$ & $739.5 \pm 9.1$ \\
\hline HOMA-IR index & $8.9 \pm 0.44$ & $1.30 \pm 0.29^{*}$ & $7.97 \pm 0.53$ & $4.03 \pm 0.55^{*}$ \\
\hline
\end{tabular}

Variable in men 


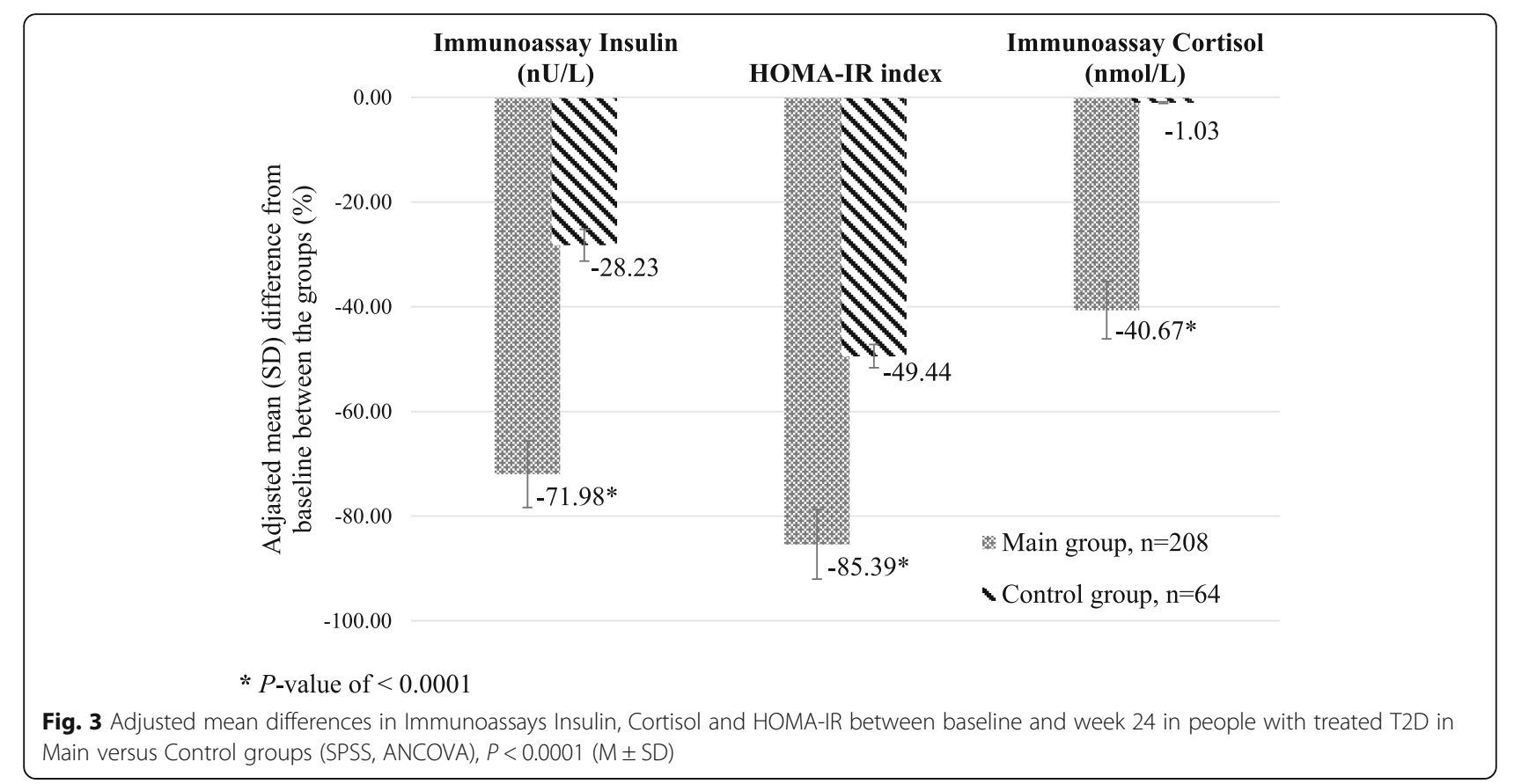

blood insulin levels, increased hemoglobin, and improved inflammation parameters. Our results confirm those of some other studies $[7,8,14]$. ANADET also decreased blood cholesterol/triglyceride levels and lipid and protein oxidative products, and increased enzymes against oxidative stress. Our study prove a potential validity of the optimal mix of caloric restriction, walking, sodium intake and sexual self-restraint behavior in effective treatment of T2D.

People with T2D eliminate through urine more sodium ions due to hyperglycemia-induced serum osmolality [15]. Blood and urine sodium became normal on a weight loss method that decreased metabolic pollutants [16], with elimination of metabolites [17]. The sodium intake in Main group subjects with T2D helped to eliminate metabolic pollutants from the body.

ANADET method improved HBMD; notably, not all weight loss methods increase HBMD [18].

People with T2D have high blood cortisol [19] and low testosterone [20]. ANADET method improved both blood cortisol and testosterone levels. Numerous studies involving both animal and human models indicate that dietinduced weight loss is associated with positive changes in leptin and ghrelin levels, insulin sensitivity and cytokine patterns [21]. However, the reciprocal influences between adiposity and hormones like insulin, leptin, ghrelin and others remain unclear.

Overweight is a biological burden for the body consuming additional trophic, immunological, antitoxic, excretion function [22]. The ANADET method metabolizes of "old lipids", leading to loss of fat mass only and to increase in muscle, water and bone masses. The patients experienced side effects related to symptoms of metabolic intoxication that is a common problem during weight loss. Adipose tissue can indeed absorb different persistent organic pollutants [23], and important role of adiposity in storing of pollutants has been outlined [24, 25]. ANADET method allows to: 1) control the elimination of metabolic endproducts; 2) switch on lipolysis; 3 ) reuse of interim metabolites. Physical exercise and mandatory salt intake are important to decrease in metabolic wastes. If sodium ions are a main transporter in the body, then exercise improves the endothelial nitric oxide and prostaglandins pathways [26]. Sexual self-restraint allows to save endogenous androgens in both genders $[27,28]$.

The ability to accumulate adipose tissue is one of the most important adaptive mechanism for survival [29]. However, we are now observing a steady increase in obesity and related diseases [1-4].

\section{Study limitation}

Published studies about positive role of weight loss in people with T2D are limited in scope and number. A limitation of our study is short duration. We acknowledge the clinical trial had approximately $8 \%$ of the randomly assigned population dropped out prior to completion. We should perform a multicenter prospective clinical randomized controlled trial. Further research is needed.

\section{Conclusions}

In people with $\mathrm{T} 2 \mathrm{D}$ an increased in fat mass is paralleled by reduction in muscle, bone, and water masses. Increased fat mass leads to increase bioimpedance and metabolic aging. Our results indicate that the weight loss 
method called ANADET can be an effective treatment for people with T2D. The method, aimed to cure and control metabolic intoxication, improves glycaemia, insulin resistance, lipids and hormones, electrolyte and biochemical outcomes, reactive oxygen species, instrumental parameter, and allows drugs reduction up to its complete withdrawal.

\begin{abstract}
Abbreviations
ANADET: Analimentary detoxication; AOPP: Advanced oxidation protein products; BMI: Body mass index; Cl: Confidence intervals; ESR: Erythrocyte sedimentation rate; HbA1c: Glycosylated hemoglobin A1c; HBMD: Heel bone mineral density; HOMA: Homeostasis Model Assessment; IDF: International Diabetes Federation; IR: Insulin resistance; M: Mean; MDA: Malondialdehyde; OGTT: Oral glucose tolerance test; OR: Odds ratios; ROS: Reactive oxygen species; SD: Standard deviation; SEM: Standard error of the mean; SOD: Superoxide dismutase; T2D: Type 2 diabetes mellitus; WC: Waist circumference; WHO: World Health Organization
\end{abstract}

\section{Acknowledgements}

We are grateful to the scientific staff of the "Scientific Research Institute of Cardiology and Internal diseases" and to professor Abylaiuly Zhanghentkhan (Kazakh National Medical University, Endocrinology Department) and professor Sandro Vento (Nazarbayev University) for reviewing the manuscript

\section{Funding}

Ministry of Health of the Republic of Kazakhstan Grants: One for 2003-2005 years with a trial national registration of \#0103RK00112 and a code of 0.0376 at the National Center for Scientific and Technical Information of the Republic of Kazakhstan and another for 2009-2011 years with a trial registration of \#0109RK00079 and a code of 0.0390 .

The funding body did not take part either in the design of the study and collection, analysis, or in the interpretation of the data and in writing the manuscript.

\section{Availability of data and material}

ClinicalTrials.gov Identifier: NCT02503865. Retrospectively Registered: November 2015

\section{Authors' contributions}

KO: writing of the paper, study design, collection of the clinical data, diagnosis and treatment of the patients, bibliography review, statistical analysis, data interpretation. BD: study design, data interpretation, writing of the discussion, bibliography and paper review. GT: study design, diagnosis and treatment of the patients, data interpretation, bibliography and paper review. $A D$ : study design, writing the methods, data interpretation, paper review. MG: preparation of the statistical data in Excel, collection of the clinical data, bibliography and paper review, data interpretation "statistical analysis, writing of the Methods. AS: writing of the discussion, statistical analysis, paper review. Al: patient diagnosis and treatment, writing of the methods/results, paper review. Al: collection of the clinical data, preparation of statistical data in Excel, patient diagnosis, bibliography search and review. All authors read and approved the final manuscript.

\section{Competing interests}

The authors declare that they have no competing interests.

\section{Consent for publication}

All the authors of the article have agreed to publish the manuscript.

\section{Ethics approval and consent to participate}

The Ethical Committee of the Scientific Institute of Cardiology and Internal Diseases (phone: +7-727-2796751, +7-727-2676851; e-mails: ncvb@of.kz; ncvb_cardio@of.kz) approved the study (Approval protocol number is \#18 of 12.05.2005. Board Affiliation: Health Ministry of Kazakhstan).

\section{Author details}

${ }^{1}$ Metabolic Syndrome Department, Nazarbayev University Medical Center, Street Baitursynuly, 5, fl. 601, 010000 Astana, Kazakhstan. ${ }^{2}$ Faculty of
Pathology and Forensic Medicine, Medical University Astana, Astana, Kazakhstan. ${ }^{3}$ Faculty of Cardiology, Medical University Astana, Astana, Kazakhstan. ${ }^{4}$ Department of Endocrinology, Republican Diagnostic Center at Nazarbayev University Medical Center, Astana, Kazakhstan. ${ }^{5}$ Faculty of Internal Medicine, Karaganda State Medical University, Karaganda, Kazakhstan. ${ }^{6}$ Neurodevelopmental Services, Richmond Healthcare Civic Centre, Twickenham, London, UK. ${ }^{7}$ Department of Endocrinology, National Scientific Cardiac Surgery Center, Astana, Kazakhstan. ${ }^{8}$ Department of Endocrinology, Medical University Astana, Astana, Kazakhstan.

Received: 4 November 2016 Accepted: 21 January 2017

Published online: 31 January 2017

\section{References}

1. Global report on diabetes. World Health Organization, Geneva, 2016. http://apps.who.int/iris/bitstream/10665/204871/1/9789241565257_eng. pdf. Accessed 7 Apr 2016.

2. Shi YH, Frank FB. The global implications of diabetes and cancer. Lancet. 2014;383(9933):1947-8.

3. Vos T, Flaxman AD, Naghavi M, Lozano R, Michaud C, Ezzati M, et al. Years lived with disability for 1160 sequelae of 289 diseases and injuries 19902010: a systematic analysis for the Global Burden of Disease Study 2010. Lancet. 2012;380(9859):2163-96.

4. Jansson SP, Svardsudd K, Andersson DK. Effects of fasting blood glucose levels and blood pressure and treatment of diabetes and hypertension on the incidence of cardiovascular disease: a study of 740 patients with incident Type 2 diabetes with up to 30 years' follow-up. Diabet Med. 2014; 31(9):1055-63.

5. Guariguata L, Whiting DR, Hambleton I, Beagley J, Linnenkamp U, Shaw JE. Global estimates of diabetes prevalence for 2013 and projections for 2035 Diabetes Res Clin Pract. 2014;103(2):137-49.

6. Wolf AM, Conaway MR, Crowther JQ, Hazen KY, Nadler J, Oneida B, et al. Improving Control with Activity and Nutrition (ICAN) Study. Translating lifestyle intervention to practice in obese patients with type 2 diabetes: Improving Control with Activity and Nutrition (ICAN) study. Diabetes Care. 2004;27(7):1570-6.

7. Snel M, Gastaldelli A, Ouwens DM, Hesselink MK, Schaart G, Buzzigoli E, et al. Effects of adding exercise to a 16-week very low-calorie diet in obese, insulin-dependent type 2 diabetes mellitus patients. J Clin Endocrinol Metab. 2012;97(7):2512-20

8. Goday A, Bellido D, Sajoux I, Crujeiras AB, Burguera B, García-Luna PP, et al. Short-term safety, tolerability and efficacy of a very low-calorie-ketogenic diet interventional weight loss program versus hypocaloric diet in patients with type 2 diabetes mellitus. Nutr Diabetes. 2016;6(9):e230

9. Ohkawa H, Ohishi N, Yagi K. Assay for lipid peroxides in animal tissues by thiobarbituric acid reaction. Anal Biochem. 1979;95(2):351-8.

10. Misra $\mathrm{H}$, Fridrovich I. The role of superoxide anion in the autooxidation of epinephrine and a simple assay for superoxide dismutase. J Biol Chem. 1972;247:3170-5.

11. Witko-Sarsat V, Friedlander M, Capeillere-Blandin C, Nguyen-Khoa T, Nguyen AT, Zingraff J, et al. Advanced oxidation protein products as a novel marker of oxidative stress in uremia. Kidney Int. 1996:49(5):1304-13.

12. Oshakbayev KP. In: Abylaiuly Z, editor. Clinical management of metabolic syndrome. Practice guidance. Almaty: Ziat Press; 2007. p. 326.

13. Jensen MD, Ryan DH, Apovian CM, Ard JD, Comuzzie AG, Donato KA, et al. 2013 AHA/ACC/TOS Guideline for the Management of Overweight and Obesity in Adults: A Report of the American College of Cardiology/ American Heart Association Task Force on Practice Guidelines and The Obesity Society. J Am Coll Cardiol. 2014;63(25):2985-3023.

14. Franz MJ, Boucher JL, Rutten-Ramos S, VanWormer JJ. Lifestyle weight-loss intervention outcomes in overweight and obese adults with type 2 diabetes: a systematic review and meta-analysis of randomized clinical trials. J Acad Nutr Diet. 2015;115(9):1447-63.

15. Liamis G, Liberopoulos E, Barkas F, Elisaf M. Diabetes mellitus and electrolyte disorders. World J Clin Cases. 2014;2(10):488-96.

16. Lee Y, Kim K, Kim S, Hong N, Lee S, Lee D. Prospective associations between persistent organic pollutants and metabolic syndrome: A nested casecontrol study. Sci Total Environ. 2014;496:219-25.

17. Lemke H, Carver T, Court O, Andersen R. The impact of excess weight loss on bone mineral density ten years following bariatric surgery. Can J Diabetes. 2013;37(2):S257. 
18. Chiodini I, Adda G, Scillitani A, Coletti F, Morelli V, Di Lembo S, et al. Cortisol secretion in patients with type 2 diabetes: relationship with chronic complications. Diabetes Care. 2007;30(1):83-8.

19. Wang $C$, Jackson $G$, Jones TH, Matsumoto AM, Nehra A, Perelman MA, et al. Low testosterone associated with obesity and the metabolic syndrome contributes to sexual dysfunction and cardiovascular disease risk in men with type 2 diabetes. Diabetes Care. 2011;34(7):1669-75.

20. Gavrieli A, Mantzoros CS. Novel molecules regulating energy homeostasis: physiology and regulation by macronutrient intake and weight loss. Endocrinol Metab (Seoul). 2016;31(3):361-72.

21. Bluher M. Adipose tissue dysfunction in obesity. Exp Clin Endocrinol Diabetes. 2009;117:241-50.

22. Dirinck EL, Dirtu AC, Govindan M, Covaci A, Van Gaal LF, Jorens PG. Exposure to persistent organic pollutants: relationship with abnormal glucose metabolism and visceral adiposity. Diabetes Care. 2014;37:1951-8.

23. Pestana D, Faria G, Sa C, Fernandes VC, Teixeira D, Norberto S, et al. Persistent organic pollutant levels in human visceral and subcutaneous adipose tissue in obese individuals-depot differences and dysmetabolism implications. Environ Res. 2014;133:170-7.

24. Lee D-H, Porta M, Jacobs Jr DR, Vandenberg LN. Chlorinated persistent organic pollutants, obesity, and type 2 diabetes. Endocr Rev. 2014;35(4):557-601.

25. Bruder-Nascimento T, Silva ST, Boer PA, Cordellini S. Effects of exercise training on stress-induced vascular reactivity alterations: role of nitric oxide and prostanoids. Braz J Phys Ther. 2015;19(3):177-85.

26. Jiang $M$, Xin J, Zou $Q$, Shen JW. A research on the relationship between ejaculation and serum testosterone level in men. J Zhejiang Univ Sci. 2003; 4(2):236-40.

27. Hamilton $L D$, Meston $C M$. The effects of partner togetherness on salivary testosterone in women in long distance relationships. Horm Behav. 2010; 57(2):198-202.

28. Saltiel AR. Insulin resistance in the defense against obesity. Cell Metab. 2012 15(6):798-804

29. Neeland IJ, Ayers CR, Rohatgi AK, Turer AT, Berry JD, Das SR, et al. Associations of visceral and abdominal subcutaneous adipose tissue with markers of cardiac and metabolic risk in obese adults. Obesity (Silver Spring). 2013;21:E439-47.

\section{Submit your next manuscript to BioMed Central and we will help you at every step:}

- We accept pre-submission inquiries

- Our selector tool helps you to find the most relevant journal

- We provide round the clock customer support

- Convenient online submission

- Thorough peer review

- Inclusion in PubMed and all major indexing services

- Maximum visibility for your research

Submit your manuscript at www biomedcentral.com/submit

) Biomed Central 